\title{
Sweet peppers discrimination according to agronomic production mode and maturation stage using a chemical-sensory approach and an electronic tongue
}

\author{
Rosa Guilherme ${ }^{\mathrm{a}, \mathrm{b}}$, Nuno Rodrigues ${ }^{\mathrm{c}}$, Ítala M.G. Marxc, Luís G. Dias ${ }^{\mathrm{c}}$, Ana C.A. Veloso ${ }^{\mathrm{d}, \mathrm{e}}$, \\ Ana Cristina Ramos ${ }^{\mathrm{f}}$, António M. Peres ${ }^{\mathrm{c}}$, José Alberto Pereira ${ }^{\mathrm{c}, *}$ \\ ${ }^{a}$ Instituto Politécnico de Coimbra, ESAC, Coimbra, Portugal \& CERNAS-Centro de Estudos de Recursos Naturais, Ambiente e Sociedade, Coimbra, Portugal \\ ${ }^{\mathrm{b}}$ GeoBioTec, Faculdade de Ciências e Tecnologia, Universidade Nova de Lisboa, Caparica, Portugal \\ ${ }^{\mathrm{c}}$ Centro de Investigação de Montanha (CIMO), ESA, Instituto Politécnico de Bragança, Bragança, Portugal \\ ${ }^{\mathrm{d}}$ Instituto Politécnico de Coimbra, ISEC, DEQB, Coimbra, Portugal

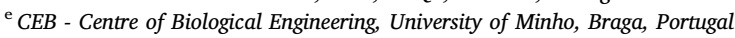 \\ ${ }^{\mathrm{f}}$ Instituto Nacional de Investigação Agrária e Veterinária (INIAV, I.P.), Oeiras, Portugal
}

\section{A R T I C L E I N F O}

\section{Keywords:}

Sweet peppers

Organic/conventional production

Maturation stage

Electronic tongue, Chemometrics

\begin{abstract}
A B S T R A C T
The demand for organic foods has increased worldwide, in particular due to the association with healthier, more nutritious and tasty products, being a clear trend on sweet peppers' consumption. Thus, this study aimed to evaluate the effects of agronomic production mode (conventional and organic) and maturation stage (associated to green, turning and red colours) on the chemical-sensory attributes of peppers grown in open field. It was found that organic peppers had a better visual/tactile aspect (greater firmness and more intense colours) but lower chemical quality (lower titratable acidity and total soluble solids). On the other hand, red peppers (higher maturation stage) had lower visual-tactile quality but higher chemical quality. From sensory analysis, conventional peppers had better overall aspect, colour intensity-homogeneity and brightness. Then again, the maturation stage of peppers mostly influenced the sensory visual attributes, being turning colour peppers the less appreciated, although organic red peppers were less succulent and had a lower global quality. Even so, the chemical-sensory parameters could be used to discriminate peppers taking into account the agronomic production mode and the maturation stage/colour $(79 \pm 12 \%$ of correct classifications for the repeated K-fold cross-validation procedure). However, a trained sensory panel is required, which can be a major drawback considering their scarcity. This limitation was successfully overcome by using a potentiometric electronic tongue, which allowed discriminating the peppers with a higher predictive sensitivity (85 $\pm 9 \%$ ), showing that this device could be used as an accurate taste sensor for the qualitative analysis of sweet peppers.
\end{abstract}

\section{Introduction}

Sweet peppers (Capsicum annuum L.) belong to the Solanaceae family and are cultivated worldwide, being a highly consumed food due to their attractive colour, pungency, succulence and typical aroma [1]. Fresh and processed fruits of different varieties have different colours, from green and white (unripe fruits) to yellow, orange and red (ripe fruits), corresponding to distinct stages of maturation; different sweet and spicy levels; as well as, different shapes, from large to thin fruits [2]. Sweet peppers are commonly produced under conventional or organic farming modes, being the latter based on sustainable and environmentally practices, where the use of pesticides and synthetic fertilizers is forbidden. An increasing worldwide demand for organic products has been observed, mainly due to the consumers growing concerns with health and environmental issues [3-5]. The quality of sweet peppers as well as of other fruits and vegetables can be established taking into account physical, chemical and sensory attributes such as appearance, flavour, texture and nutritional value [6]. Several researches have focused on peppers' quality characteristics and their evolution during storage or due to different agronomic treatments. The chemical composition, namely volatile and/or non-volatile components and the antioxidant capacity of cultivated or wild species has been

\footnotetext{
* Corresponding author at: Centro de Investigação de Montanha (CIMO), ESA, Instituto Politécnico de Bragança, Campus de Santa Apolónia, 5300-253 Bragança, Portugal.

E-mail address: jpereira@ipb.pt (J.A. Pereira).
} 
highlighted and used for variety identification, geographical origin assessment and/or postharvest chemical/sensory evaluation [1,7-9]. Although the chemical characterization of a food matrix is of utmost relevance, the flavour (i.e., the overall sensation provided by the interaction of taste, aroma, mouth fell, sight and sound) plays a key role on the consumer's preference, and so, became a main critical quality parameter in pepper production [1]. The flavour characteristics are highly dependent on the fruit variety but also on the growing conditions/production modes (e.g., conventional or organic practices) [10] and on the fruit's maturation stage [11]. Despite the relevance of flavour, specific research addressing sweet pepper sensory analysis is scarce [1]. Eggink et al. [1] showed that individual taste attributes of sweet peppers could be linked to volatile and non-volatile compounds of peppers. However, sensory analysis performed by trained panellists is a time consuming and expensive task. Furthermore, the low number of samples that may be evaluate per day, lack of reference standards, the intrinsic human subjective found even for trained panellists, together with the scarcity of trained sensory panels for a specific food matrix, makes sensory analysis a hard task $[12,13]$.

Thus, emerging sensor-based electrochemical devices have been proposed for sensory analysis, aiming to minimize or even overcoming the abovementioned drawbacks. In this context, it has been highlighted the possibility of using potentiometric and voltammetric electronic tongues (E-tongues) as taste sensors for assessing basic tastes (e.g., acid, pungent, salty, sweet and umami sensations) as well as positive attributes (e.g., bitter, fruity and green sensations) and negative attributes (e.g., rancid, wine-vinegary, musty, fusty, zapateria, butyric, and putrid sensations) of different foodstuffs [14-22].

This work intended to evaluate the effects of the production mode (i.e., conventional versus organic farming practices) and of the maturation stage (linked to the green, turning colour and red peppers) on physicochemical and sensory attributes of sweet peppers. Also, it was intended to evaluate the possibility of applying a potentiometric Etongue comprising lipid-polymeric sensor membranes, coupled with chemometric tools for correctly classifying the sweet peppers according to the agronomic production mode/maturation stage. Finally, it was aimed to compare the E-tongue classification performance with that achieved based on the assessment performed by trained panellists.

\section{Materials and methods}

\subsection{Sweet peppers production mode and sampling}

Two producers of sweet peppers (Capsicum annuum L.), located in the central region of Portugal (Coimbra), were selected. One of the producers followed the organic production European Commission guidelines (Council Regulation (EC) $n^{\circ} 834 / 2007$ of 28 June 28, 2007) whereas the other followed conventional agriculture without any limitations on the use of pesticides. In both fields, the soil had similar acidity, with $\mathrm{pH}\left(\mathrm{H}_{2} \mathrm{O}\right)$ 6.0-6.4, organic matter around 1.5-2.0\% and similar physical and chemical characteristics. Sweet pepper seedlings, from Entinas variety, were put in the soil in the last week of May 2018 and were grown under open field conditions. In both fields, a drip irrigation system was installed and the nutritional requirements were supplied by horse manure, in the organic field, and by chemical fertilizers, in the conventional one. In the middle of September 2018, from each producer (organic and conventional) sweet peppers were harvested at three different (increasing) maturation stages (corresponding to green, turning colour and red sweet peppers, respectively). Altogether, five independent batches, of about $2 \mathrm{~kg}$ each, of each agronomic production mode and maturation stage were collected, totalizing 30 independent samples. Sweet peppers were then washed, cleaned, dried, and further stored under refrigeration $\left(\sim 4^{\circ} \mathrm{C}\right)$ until analysis.

\subsection{Sweet peppers chemical, colour and sensory profiles}

The sweet peppers collected were subjected to different physicochemical analysis, including texture, colour, titratable acidity (TA), $\mathrm{pH}$ and total soluble solids (TSS), using conventional analytical techniques.

The maximum penetration force $(\mathrm{N})$ was evaluated with a HD plus texture analyser (Stable Microsystems, Godalming, UK). The evaluation was made by penetration with a $2 \mathrm{~mm}$ cylinder probe, with a $5.0 \mathrm{~kg}$ $(50 \mathrm{~N})$ charge cell, and a test speed of $1.0 \mathrm{~mm} / \mathrm{s}$ and $10 \mathrm{~mm}$ length. The colour was evaluated using a colorimeter Minolta CR-200b (Osaka, Japan), using the CIELAB scale, namely: $\mathrm{L}^{*}, \mathrm{a}^{*}$ and $\mathrm{b}^{*}$ coordinates, where $L^{*}$ varies between 0 (black) and 100 (white), the chromatic a* axis extends from green $\left(-a^{*}\right)$ to red $\left(+a^{*}\right)$, and the chromatic $b^{*}$ axis extends from blue $\left(-b^{*}\right)$ to yellow $\left(+b^{*}\right)$. The evaluations were made in three fruits per sample and for each fruit in four points of the epidermis, with an $8 \mathrm{~mm}$ reading aperture, diffuse lighting and an observation angle of $0^{\circ}$ under artificial daylight (CIE D65 standard illuminant), being calculated the CIELAB colour coordinates. The titratable acidity (TA) was determined by titrimetric analysis, consisting of a titration with a $\mathrm{NaOH}$ solution $(0.10 \mathrm{~mol} / \mathrm{L})$. Approximately, $10 \mathrm{~g}$ of each sample (previously ground) was mixed with $50 \mathrm{~mL}$ of water and put on heating under reflux for $30 \mathrm{~min}$. Then, the resultant solution was transferred to a glass balloon of $100 \mathrm{~mL}$ and after filtration a precise volume $(20 \mathrm{~mL})$ was transferred to a beaker with a stirrer. Then, the $\mathrm{pH}$ of the solution was monitored continuously in order to obtain the titration curve. The $\mathrm{pH}$ at the equivalence point was established as 8.1, as indicated in the Portuguese regulation (NP-1421, 1977). The values were expressed on $\mathrm{mg}$ citric acid /100 $\mathrm{g}$ fresh weight (fw). $\mathrm{pH}$ values were evaluated using a Crison-Micro pH 2002 (Crison, Barcelona, Spain) potentiometer. The solution obtained for the acidity determination (after filtration) was also used to measure total soluble solids (TSS) contents ( ${ }^{\circ} \mathrm{Brix}$ ), at $20^{\circ} \mathrm{C}$, in an ATAGO refractometer (Saitama, Japan).

Sensory analysis of peppers was performed by 8 trained sensory panel from the National Institute for Agricultural and Veterinary Research (INIAV, Portugal). The attributes evaluated by the panellists according to the guidelines of the International Organization for Standardization (ISO 11036: 1994; ISO 4121: 2003; ISO 13299: 2016), with some adaptations. From each batch, three peppers pieces of $2 \mathrm{~cm}^{2}$ were evaluated considering the aspect, intensity and homogeneity of colour, brightness, aroma, sweet, bitter, acid, pungent, taste, hardness, fibrousness, crustiness, succulence and global quality. All of these parameters were assessed using a continuous unstructured scale from 1 (absence of sensation) to 11 (maximum intensity).

\subsection{E-tongue analysis}

\subsubsection{Apparatus}

A lab-made potentiometric E-tongue multi-sensor device comprising two cylindrical arrays has been used (Fig. 1). Each array contained 20 lipid polymeric cross-sensitive sensor membranes (40 sensors in total). Since the E-tongue sensors are non-specific with cross-sensitivity and poor selectivity [23], 40 sensors were used to ensure that a representative potentiometric profile related to the chemical fingerprint of each sample could be recorded. The sensors compositions (lipid additive, 3\%; plasticizer, 32\%; and, polyvinyl chloride, 65\%) have been previously described [21] and are shown in Fig. 1. It should be remarked that the sensor membranes used in this study had a higher contact surface $\left(\sim 25 \mathrm{~mm}^{2}\right)$ and thickness, allowing a better signal stability and the detection performance. Lipid polymeric sensor membranes were used since they allowed establishing electrostatic or hydrophobic interactions between the membranes and the polar compounds of the target samples $[19,24,25]$. These membranes contain polar (with negative or positive polarities) and non-polar regions that promote the interactions and the potentiometric assessment of samples' 


\begin{tabular}{|c|c|c|c|}
\hline E-tongue & \multirow{7}{*}{$\begin{array}{l}\text { Sensor lipid } \\
\text { membranes } \\
\text { arrays } \\
\text { and } \\
\text { pH electrode }\end{array}$} & \multirow{2}{*}{$\begin{array}{l}\text { Sensor code } \\
S 1: 1(S 2: 1)\end{array}$} & \multirow{2}{*}{$\begin{array}{l}\text { Plasticizer (32\%) + Lipid additive ( } 3 \%) \\
\text { bis(1-butylpentyl) adipate + methyltrioctylammonium chloride }\end{array}$} \\
\hline & & & \\
\hline & & $\mathrm{S} 1: 2(\mathrm{~S} 2: 2)$ & bis(1-butylpentyl) adipate + oleic acid \\
\hline & & $\mathrm{S} 1: 3(\mathrm{~S} 2: 3)$ & bis(1-butylpentyl) adipate + oleyl alcohol \\
\hline & & $\mathrm{S} 1: 4(\mathrm{~S} 2: 4)$ & bis(1-butylpentyl) adipate + octadecylamine \\
\hline & & $\mathrm{S} 1: 5(\mathrm{~S} 2: 5)$ & dibutyl sebacate + methyltrioctylammonium chloride \\
\hline & & $\mathrm{S} 1: 6(\mathrm{~S} 2: 6)$ & dibutyl sebacate + oleic acid \\
\hline & & $\mathrm{S} 1: 7(\mathrm{~S} 2: 7)$ & dibutyl sebacate + oleyl alcohol \\
\hline & & $\mathrm{S} 1: 8(\mathrm{~S} 2: 8)$ & dibutyl sebacate + octadecylamine \\
\hline & & $\mathrm{S} 1: 9(\mathrm{~S} 2: 9)$ & dioctyl phenylphosphonate + methyltrioctylammonium chloride \\
\hline & & $\mathrm{S} 1: 10(\mathrm{~S} 2: 10)$ & dioctyl phenylphosphonate + oleic acid \\
\hline & & $\mathrm{S} 1: 11(\mathrm{~S} 2: 11)$ & dioctyl phenylphosphonate + oleyl alcohol \\
\hline & & $\mathrm{S} 1: 12(\mathrm{~S} 2: 12)$ & dioctyl phenylphosphonate + octadecylamine \\
\hline & & S1:13 (S2:13) & 2-nitrophenyl-octylether + methyltrioctylammonium chloride \\
\hline & & $\mathrm{S} 1: 14$ (S2:14) & 2-nitrophenyl-octylether + oleic acid \\
\hline & & $\mathrm{S} 1: 15(\mathrm{~S} 2: 15)$ & 2-nitrophenyl-octylether + oleyl alcohol \\
\hline & & $\mathrm{S} 1: 16(\mathrm{~S} 2: 16)$ & 2-nitrophenyl-octylether + octadecylamine \\
\hline & & $\mathrm{S} 1: 17$ (S2:17) & tris(2-ethylhexyl)phosphate + methyltrioctylammonium chloride \\
\hline & & S1:18 (S2:18) & tris(2-ethylhexyl)phosphate + oleic acid \\
\hline & & $\mathrm{S} 1: 19(\mathrm{~S} 2: 19)$ & tris(2-ethylhexyl)phosphate + oleyl alcohol \\
\hline & & $\mathrm{S} 1: 20(\mathrm{~S} 2: 20)$ & tris(2-ethylhexyl)phosphate + octadecylamine \\
\hline & ging & & \\
\hline
\end{tabular}

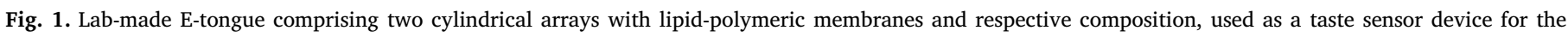
potentiometric analysis of sweet peppers.

polar compounds. It has been reported that lipid-polymeric membranes, comprising different combinations of lipid additives (e.g., methyltrioctylammonium chloride, oleic acid, oleyl alcohol, and octadecylamine) and plasticizers (e.g., bis(1-butylpentyl) adipate, dibutyl sebacate, dioctyl phenylphosphonate, 2-nitrophenyl-octylether, and tris(2ethylhexyl)phosphate), present a potentiometric semi-logarithmic quantitative response towards the concentration of different chemical compounds like, for example, phenolic aldehydes, esters, alcohol, and aldehydes [19,25,26], acids, salts, caffeine, and quinine [19,25,27]. Overall, these sensors showed sensitivities ranging from -287 to $210 \mathrm{mV} /$ decade, signal over-time stability with a relative standard deviation (\%RSD) lower than $5 \%$ and intra-day repeatabilities (\%RSD) lower than $12 \%$. The membranes were connected to a multiplexer Agilent Data Acquisition Switch Unit (model 34970A) controlled by the Agilent BenchLink Data Logger. Each potentiometric assay took $5 \mathrm{~min}$ and allowed recording the potentiometric signals of all membranes generated due to electrostatic and/or hydrophobic interactions [24]. An $\mathrm{Ag} / \mathrm{AgCl}$ double-junction glass reference electrode (Crison, 5241) was used. The same sensor coding used in previous works was adopted: each sensor was identified with a letter $\mathrm{S}$ (for sensor) followed by the number of the array ( 1 or 2 ) and the number of the membrane ( 1 to 20 , corresponding to different combinations of plasticizers and additives) (Fig. 1).

\subsubsection{E-tongue analysis: Sweet pepper sample preparation and potentiometric assays}

For the potentiometric assays, sweet peppers were processed following the procedure described by Marx et al. [19] with some modifications. From each sweet pepper sample, two rectangular portions of about $8 \mathrm{~cm} \times 6 \mathrm{~cm}$ were cut $(\sim 25 \mathrm{~g}$ per portion) and separately mashed using a Moulinex knife chopper. For each replicate, $20 \mathrm{~g}$ of mashed sweet pepper were placed in a plastic cup $(100 \mathrm{~mL})$, being then diluted with $60 \mathrm{~mL}$ of deionized water and agitated during $1 \mathrm{~min}$. The aqueous paste was left in the fridge overnight $\left(\sim 4^{\circ} \mathrm{C}\right)$, being the potentiometric analysis carried out during the next $24 \mathrm{~h}$, after letting them reach the ambient temperature $\left(\sim 20^{\circ} \mathrm{C}\right)$ and after a smooth agitation $(\sim 1 \mathrm{~min})$. So, for each sweet pepper replicate, two electrochemical assays were performed, with a third assay carried out if the potentiometric signal of any of the 40 sensors showed a coefficient of variation greater than $20 \%$ [22]. Afterwards, for data split (random establishment of training and internal-validation sets) and modelling purposes, only one electrochemical "average" signal profile per sample (i.e., per sweet pepper from the independent quintuplicate assays) was used, avoiding that data from duplicate assays of the same sweet pepper could be included into both training and validation sets [18].

\subsection{Statistical analysis}

The significant statistical effects of the agronomic production mode as well as of the maturation stages on the chemical, colour and sensory profiles of sweet peppers, was evaluated using the t-Student test and the one-way ANOVA (followed by the post-hoc multi-comparison Tukey's test if a significant statistical effect was found, i.e., $P$-value $<0.05$ ), respectively.

Principal component analysis (PCA) and linear discriminant analysis (LDA) coupled with the meta-heuristic simulated annealing (SA) variable selection algorithm were used to evaluate the unsupervised and supervised classification power of the chemical-sensory data as well as of the E-tongue signal data. The LDA-SA aimed to identify the nonredundant discriminative sub-set of independent variables by minimizing possible noise effects as well as to overcome the usual high multicollinearity of the potentiometric signals $[28,29]$. This algorithm searches the optimal conditions based on the annealing physic process that mimics the slow controlled cooling process of a heated material aiming to obtain a regular crystal lattice configuration. This metaheuristic algorithm is capable of identifying a subset of the original independent variables that allows achieving a global optimum for a given approximation criterion, selected within a large search space of other possible subsets of variables [29]. In each iteration, values of two solutions (the current subset of $\mathrm{k}$ variables and the new subset to be 
tested, also with $\mathrm{k}$ variables) are compared according to a criterion that measures their quality, for example, based on the accuracy of the classification model. The new solution is randomly selected in the neighbourhood of the current solution and tested according to the simulated annealing rules, becoming the new solution if the criterion has a best accuracy than the original one. The algorithm continues the search for new solutions until it reaches the maximum number of interactions established at the beginning of procedure. The predictive performances of the LDA-SA models were checked using the leave-oneout (LOO) and the repeated K-fold cross-validation (CV) variants. For the latter, data was randomly split into K folds and each of the folds was left out in turn (for internal validation) and the other K-1 folds were used to train the model. The held out fold was used for test purposes and the quality of the predictions was assessed using the average values of sensitivities (percentage of correct/true classifications). The K estimates are then averaged to obtain the overall resampled estimate [30]. In this work, four K-folds were used aiming to provide bias reduction by enabling the random formation of internal validation subsets (for each agronomic mode and maturation stage studied) with $25 \%$ of the initial data (containing 1-2 of the 5 independent samples/batches). The procedure was repeated $10 \times$ to evaluate the performance under stress model conditions. The repeated K-fold-CV technique allows reducing the uncertainty of the estimates, by evaluating the predictive performance of the models established using $4 \times 10$ random sub-sets for internal validation (i.e., 40 total resamples). All variables were scaled and centred before modelling to normalize the weight of each one on the final multivariate linear classification model. The unsupervised and supervised classification performances were qualitatively assessed using 3D plots of the principal or discriminant components and, for the LDA-SA models by calculating the sensitivity values (i.e., the percentage of correctly classified samples). The statistical analysis was performed using the Subselect [29] and MASS [31] packages of the open source statistical program R (version 2.15.1), at a 5\% significance level.

\section{Results}

\subsection{Chemical, colour and sensory profiles of sweet peppers}

The sweet peppers' physicochemical and sensory data, produced under agronomic conventional or organic modes and harvested at three increasing maturation stages (green, turning colour and red, respectively) are shown in Tables 1 and 2, respectively. The values determined regarding the fruit quality parameters (force, TSS, TA, pH and CIELAB colour scale) are in agreement with the majority of the vast data reported in literature for sweet peppers. Although it can be stated that values are usually of the same order of magnitude, it should be noticed that quality parameters are highly dependent on the fruit variety, maturation stage, agronomic production practices (e.g., irrigation deficit conditions, soilless media composition, radiative environment, field crops conditions, among other) and geographical origin and so, in some specific cases, differences arisen [1,7,8,32-40]. On the contrary a scarce number of works described the assessment of intensities of sensory attributes by panellists $[1,34,36]$ and, in general, the information reported cannot be easily used for comparison due to the different attributes evaluated and the different intensity scales used by the different research teams. Even so, for comparable/similar assessed sensations (e.g., acid, aroma, crunchy, hardness, juicy, pungent, salty, sweet, visual aspect), the intensities perceived, in this work, by the trained panellists are in slight agreement with those reported in the literature $[1,34,36]$.

Tables 1 and 2 show that the agronomic production mode and the maturation stage had, in general, a significant statistical effect $(P$ value $<0.05$ ) on sweet peppers' physicochemical parameters and sensory attributes. For the evaluated physicochemical parameters, and independently of the peppers' maturation stage (i.e., colour) it could be stated that organic fruits had greater firmness (evaluated based on the force data) and higher values of CIELAB colour coordinates ( $\mathrm{L}^{*}, \mathrm{a}^{*}$ and $\mathrm{b}^{*}$ ) in comparison with conventional peppers (in general, $P$-values $<$ 0.05 for $t$-Student's test, Table 1 ), which constituted a visual/tactile advantage for the former mode. An opposite inference could be observed for the other parameters, showing the organic fruits lower $\mathrm{pH}$, TA and TSS values than conventional fruits (in general, $P$-values $<$ 0.05 for $t$-Student's test, Table 1 ), showing that the latter mode would allow producing peppers richer in organic acids and with higher sugar contents, and thus with a better chemical quality. In general, the results also pointed out that, regardless the agronomic production mode, increasing peppers' maturation stage (i.e., red $>$ turning colour $>$ green) would lead to a significantly decrease trend of the fruits' firmness, the $L^{*}$ and $b^{*}$ coordinates values as well as of the $\mathrm{pH}$ values and to a significantly increase of the fruits' a* coordinate value, TA and TSS values $(P$-value $<0.05$ for one-way ANOVA and post hoc Tukey's HSD test). So, peppers at higher maturation stage would show a lower visual and tactile quality but higher chemical quality (i.e., greater levels of organic acids and sugar contents.

In which concerns the sensory analysis, the trained panellists evaluated attributes related to the visual aspect, olfactory and taste sensations. Table 2 shows that, independently of the peppers' maturation stage, the production mode only had a clear significant statistical influence on the visual aspect parameters. In fact, peppers produced following the conventional mode were scored with significantly higher ( $P$-values $<0.05$ for $t$-Student's test) values regarding the overall aspect, colour intensity and homogeneity compared to organic peppers. However, no significant difference was found regarding the brightness intensity although, higher values were expected for the organic mode taking into account their greater $L^{*}$ values (Table 1 ). On the other hand, and generally, the production mode did not have a significant effect on olfactory and gustatory attributes (i.e., aroma, acid, sweet, bitter, pungent, taste, hardness, fibrousness, crustiness, succulence) neither on the peppers' global quality. In which concerns the hardness evaluation, the anticipated greater intensities for organic peppers, based on the firmness results (Table 1), was not confirmed by the sensory analysis. Regarding the maturation stage (i.e., fruit's colour) effect on the sensory sensations evaluated, independently of the production mode, once again it could be observed that it was more significant on the visual aspect parameters (with the exception of brightness), being evident that turning colour peppers had significant lower scores regarding the overall aspect, colour intensity and homogeneity, than green and red peppers ( $P$-value $<0.05$ for one-way ANOVA and post hoc Tukey's HSD test). In which concerns the aroma and some of the basic tastes (acid, sweet, bitter, pungent and taste), although some significant differences could be found between peppers harvested at different maturation stages (i.e., different colours) and produced following different agronomic practices, the observed differences were punctual and did not have a clear trend. Once again, in which concerns the acid and sweet sensations no obvious correlation was found between them and the respective chemical parameters (TA and $\mathrm{pH}$; TSS), strengthening the need of both type of data for establishing sound inferences. Also, no significant maturation stage effect was observed for hardness, fibrousness, and crustiness, being found a significant decrease of the succulence intensity and the global quality with the increase of the maturation stage but only for organic production, indicating that red peppers were the less appreciated ones and that he organic mode could be more prone to fruit's maturation influence.

Finally, it should be pointed out the effects of the agronomic production mode on the quality of agricultural products and health benefits are not consensual. Some studies evidenced that organic fruits/vegetables are usually more aromatic, with more intense flavour, better sensory characteristics and healthier composition, although the positive impact on human health is not clear [41]. In the present work, in general, TA was higher in conventional peppers, which could be related to a higher content in organic acids. Also the $\mathrm{pH}$ values were lower in organic peppers, although the values were similar to those found for 
Table 1

Physicochemical experimental composition (mean value \pm standard deviation) and statistical differences for sweet peppers with different maturation stages (green, turning colour and red corresponding to increasing maturation, respectively) and produced under different agronomic production mode (conventional and organic farming practices).

\begin{tabular}{|c|c|c|c|c|c|c|}
\hline \multicolumn{2}{|l|}{ Parameter } & \multirow[t]{2}{*}{ Production mode } & \multicolumn{4}{|c|}{ Sweet pepper colour (i.e., maturation stage) } \\
\hline & & & Green & Turning colour & Red & $P$-value ${ }^{\mathrm{i}}$ \\
\hline \multirow{3}{*}{\multicolumn{2}{|c|}{ Force $(\mathrm{N})$}} & Organic & $\begin{array}{l}12.1 \pm 2.3^{\mathrm{a}} \\
(8.2-16.7)\end{array}$ & $\begin{array}{l}11.1 \pm 1.4^{\mathrm{a}} \\
(8.4-13.4)\end{array}$ & $\begin{array}{l}9.2 \pm 1.4^{b} \\
(7.3-12.3)\end{array}$ & $<0.0001$ \\
\hline & & Conventional & $\begin{array}{l}7.9 \pm 0.9^{b} \\
(6.5-10.0)\end{array}$ & $\begin{array}{l}9.8 \pm 1.2^{\mathrm{a}} \\
(7.2-11.7)\end{array}$ & $\begin{array}{l}7.9 \pm 1.2^{b} \\
(6.1-10.0)\end{array}$ & $<0.0001$ \\
\hline & & $P$-value ${ }^{\mathrm{ii}}$ & $<0.0001$ & 0.0001 & 0.0002 & \\
\hline \multirow[t]{9}{*}{ CIELAB colour scale } & $\mathbf{L}^{*}$ & Organic & $\begin{array}{l}37.4 \pm 1.6^{\mathrm{a}} \\
(34.2-41.3)\end{array}$ & $\begin{array}{l}37.6 \pm 3.3^{\mathrm{a}} \\
(32.0-43.9)\end{array}$ & $\begin{array}{l}34.7 \pm 2.2^{b} \\
(31 .-40.5)\end{array}$ & 0.0006 \\
\hline & & Conventional & $\begin{array}{l}36.0 \pm 2.7^{\mathrm{a}} \\
(31.9-39.8)\end{array}$ & $\begin{array}{l}33.3 \pm 2.3^{b} \\
(29.0-37.0)\end{array}$ & $\begin{array}{l}31.0 \pm 1.6^{c} \\
(27.7-33.7)\end{array}$ & $<0.0001$ \\
\hline & & $P$-value ${ }^{\text {ii }}$ & 0.0551 & $<0.0001$ & $<0.0001$ & \\
\hline & $\mathbf{a}^{*}$ & Organic & $\begin{array}{l}-11.1 \pm 1.2^{\mathrm{c}} \\
(-13.9-(-) 9.4)\end{array}$ & $\begin{array}{l}5.3 \pm 6.2^{b} \\
(-3.0-17.7)\end{array}$ & $\begin{array}{l}22.3 \pm 3.8^{\mathrm{a}} \\
(15.1-28.3)\end{array}$ & $<0.0001$ \\
\hline & & Conventional & $\begin{array}{l}-12.4 \pm 2.1^{\mathrm{c}} \\
(-15.5-(-) 8.9)\end{array}$ & $\begin{array}{l}9.1 \pm 11.0^{b} \\
(-11.7-29.1)\end{array}$ & $\begin{array}{l}19.4 \pm 4.0^{\mathrm{a}} \\
(12.0-26.4)\end{array}$ & $<0.0001$ \\
\hline & & $P$-value $\mathrm{ii}^{\mathrm{ii}}$ & 0.0194 & 0.1936 & 0.0265 & \\
\hline & $\mathbf{b}^{*}$ & Organic & $\begin{array}{l}14.7 \pm 2.9^{b} \\
(9.0-22.5)\end{array}$ & $\begin{array}{l}17.8 \pm 4.2^{\mathrm{a}} \\
(11.9-27.0)\end{array}$ & $\begin{array}{l}15.4 \pm 2.7^{\mathrm{a}, \mathrm{b}} \\
(11.9-21.7)\end{array}$ & 0.0120 \\
\hline & & Conventional & $\begin{array}{l}17.0 \pm 4.2^{\mathrm{a}} \\
(10.6-22.5)\end{array}$ & $\begin{array}{l}13.3 \pm 2.8^{b} \\
(9.2-19.3)\end{array}$ & $\begin{array}{l}11.6 \pm 2.3^{b} \\
(8.9-19.0)\end{array}$ & $<0.0001$ \\
\hline & & $P$-value ${ }^{\mathrm{ii}}$ & 0.0551 & 0.0003 & $<0.0001$ & \\
\hline \multirow{3}{*}{\multicolumn{2}{|c|}{ Titratable acidity(TA, mg citric acid/100 $\mathrm{g}$ fw) }} & Organic & $\begin{array}{l}63 \pm 4^{b} \\
(56-69)\end{array}$ & $\begin{array}{l}152 \pm 1^{\mathrm{a}} \\
(114-175)\end{array}$ & $\begin{array}{l}162 \pm 16^{\mathrm{a}} \\
(145-189)\end{array}$ & $<0.0001$ \\
\hline & & Conventional & $\begin{array}{l}67 \pm 9^{b} \\
(55-83)\end{array}$ & $\begin{array}{l}168 \pm 13^{a} \\
(147-189)\end{array}$ & $\begin{array}{l}\mathbf{1 7 1} \pm \mathbf{1 8}^{\mathrm{a}} \\
(151-202)\end{array}$ & $<0.0001$ \\
\hline & & $P$-value ${ }^{\mathrm{ii}}$ & 0.1404 & 0.0155 & 0.1576 & \\
\hline \multirow{3}{*}{\multicolumn{2}{|c|}{$\mathrm{pH}$}} & Organic & $\begin{array}{l}6.2 \pm 0.1^{a} \\
(6.1-6.3)\end{array}$ & $\begin{array}{l}5.0 \pm 0.1^{b} \\
(4.9-5.2)\end{array}$ & $\begin{array}{l}5.0 \pm 0.1^{b} \\
(4.7-5.1)\end{array}$ & $<0.0001$ \\
\hline & & Conventional & $\begin{array}{l}\mathbf{6 . 0} \pm 0.5^{\mathrm{a}} \\
(5.9-6.6)\end{array}$ & $\begin{array}{l}5.5 \pm 0.4^{b} \\
(5.1-5.6)\end{array}$ & $\begin{array}{l}5.2 \pm 0.1^{c} \\
(5.0-5.3)\end{array}$ & $<0.0001$ \\
\hline & & $P$-value ${ }^{\mathrm{ii}}$ & 0.2483 & $<0.0001$ & 0.0001 & \\
\hline \multirow{3}{*}{\multicolumn{2}{|c|}{ Total soluble solids(TSS, ${ }^{\circ}$ Brix) }} & Organic & $\begin{array}{l}3.8 \pm 0.3^{b} \\
3.2-4.4)\end{array}$ & $\begin{array}{l}\mathbf{5 . 8} \pm \mathbf{0 . 8 ^ { \mathrm { a } }} \\
(4.6-7.0)\end{array}$ & $\begin{array}{l}5.8 \pm 0.7^{a} \\
(4.4-7.2)\end{array}$ & $<0.0001$ \\
\hline & & Conventional & $\begin{array}{l}4.4 \pm 0.5^{b} \\
(3.9-5.7)\end{array}$ & $\begin{array}{l}7.8 \pm 0.7^{a} \\
(6.2-8.9)\end{array}$ & $\begin{array}{l}7.6 \pm 0.5^{\mathrm{a}} \\
(6.9-8.3)\end{array}$ & $<0.0001$ \\
\hline & & $P$-value ${ }^{\mathrm{ii}}$ & 0.0003 & $<0.0001$ & $<0.0001$ & \\
\hline
\end{tabular}

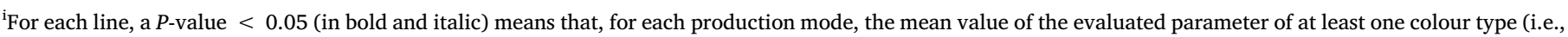

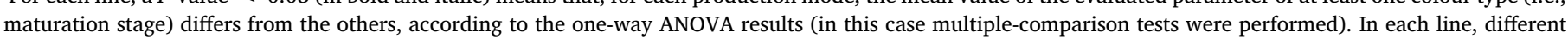

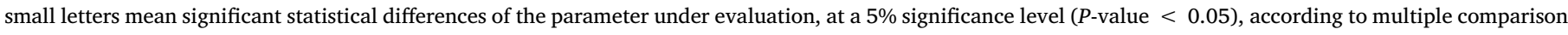
Tukey's HSD test.

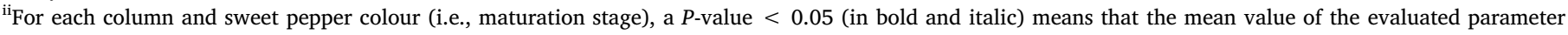
varied significantly with the production mode, according to $t$-Student test.

conventional mode, and so, this observation could be tentatively attributed to slight differences in soil characteristics. The TSS values were higher in conventional peppers, which may indicate that the plants grown under conventional mode were healthier from a nutritional point of view, allowing obtaining peppers with higher sugar levels and consequently with a better quality. In which concerns the fruit's maturation effect (i.e., pepper's colour) the results showed a marked significant effect on both physicochemical and sensory characteristics. Within the mode of production, differences were observed with fruit maturation, from green to red. As well, independently of the fruit's 
Table 2

Sensory attributes (mean value \pm standard deviation) perceived by trained panellists and statistical differences for sweet peppers with different maturation stages (green, turning colour and red corresponding to increasing maturation, respectively) and produced under different agronomic production mode (conventional and organic farming practices).

\begin{tabular}{|c|c|c|c|c|c|}
\hline \multirow[t]{2}{*}{ Sensory attribute ${ }^{i}$} & \multirow[t]{2}{*}{ Production mode } & \multicolumn{3}{|c|}{ Sweet pepper colour (i.e., maturation stage) } & \multirow[b]{2}{*}{$P$-value ${ }^{\mathrm{ii}}$} \\
\hline & & Green & Turning colour & Red & \\
\hline \multirow[t]{3}{*}{ Aspect } & Organic & $\begin{array}{l}9.0 \pm 1.3^{\mathrm{a}} \\
(6.0-11.0)\end{array}$ & $\begin{array}{l}\mathbf{8 . 0} \pm 1 . \mathbf{8}^{\mathrm{b}} \\
(4.4-10.4)\end{array}$ & $\begin{array}{l}8.2 \pm 1.5^{\mathrm{a}, \mathrm{b}} \\
(4.2-10.4)\end{array}$ & 0.0094 \\
\hline & Conventional & $\begin{array}{l}9.5 \pm 1.0^{\mathrm{a}} \\
(6.8-10.8)\end{array}$ & $\begin{array}{l}8.4 \pm 1.4^{b} \\
(4.5-10.8)\end{array}$ & $\begin{array}{l}9.3 \pm 1.2^{\mathrm{a}} \\
(7.0-11.0)\end{array}$ & 0.0003 \\
\hline & $P$-value ${ }^{\mathrm{iii}}$ & 0.0644 & 0.1897 & 0.0004 & \\
\hline \multirow[t]{3}{*}{ Colour intensity } & Organic & $\begin{array}{l}7.9 \pm 1.7^{\mathrm{a}} \\
(4.3-10.1)\end{array}$ & $\begin{array}{l}\mathbf{6 . 4} \pm 1 . \mathbf{8}^{\mathrm{b}} \\
(3.2-10.3)\end{array}$ & $\begin{array}{l}7.9 \pm 1.9^{\mathrm{a}} \\
(4.2-10.6)\end{array}$ & 0.0002 \\
\hline & Conventional & $\begin{array}{l}8.7 \pm 1.5^{\mathrm{a}, \mathrm{b}} \\
(5.0-10.8)\end{array}$ & $\begin{array}{l}\mathbf{8 . 1} \pm \mathbf{1 . 3 ^ { b }} \\
(5.3-10.2)\end{array}$ & $\begin{array}{l}9.2 \pm 1.3^{\mathrm{a}} \\
(6.0-11.0)\end{array}$ & 0.0024 \\
\hline & $P$-value ${ }^{\mathrm{iii}}$ & 0.0407 & $<0.0001$ & 0.0009 & \\
\hline \multirow[t]{3}{*}{ Colour homogeneity } & Organic & $\begin{array}{l}9.0 \pm 1.1^{\mathrm{a}} \\
(5.5-10.5)\end{array}$ & $\begin{array}{l}4.8 \pm 2.2^{b} \\
(1.5-9.6)\end{array}$ & $\begin{array}{l}8.4 \pm 1.7^{\mathrm{a}} \\
(2.6-10.3)\end{array}$ & $<0.0001$ \\
\hline & Conventional & $\begin{array}{l}9.6 \pm 1.1^{\mathrm{a}} \\
(7.1-11.0)\end{array}$ & $\begin{array}{l}6.2 \pm 2.5^{b} \\
(1.9-10.2)\end{array}$ & $\begin{array}{l}9.5 \pm 1.3^{\mathrm{a}} \\
(5.2-11.0)\end{array}$ & $<0.0001$ \\
\hline & $P$-value ${ }^{\mathrm{iii}}$ & 0.0254 & 0.0094 & 0.0008 & \\
\hline \multirow[t]{3}{*}{ Brightness } & Organic & $\begin{array}{l}7.8 \pm 1.3 \\
(3.7-9.8)\end{array}$ & $\begin{array}{l}7.3 \pm 1.4 \\
(3.1-9.4)\end{array}$ & $\begin{array}{l}7.5 \pm 1.6 \\
(3.6-9.7)\end{array}$ & 0.3592 \\
\hline & Conventional & $\begin{array}{l}8.2 \pm 1.4 \\
(6.1-10.5)\end{array}$ & $\begin{array}{l}7.6 \pm 1.4 \\
(4.9-9.8)\end{array}$ & $\begin{array}{l}8.1 \pm 1.3 \\
(5.3-10.2)\end{array}$ & 0.1763 \\
\hline & $P$-value ${ }^{\mathrm{iii}}$ & 0.1666 & 0.2620 & 0.0819 & \\
\hline \multirow[t]{3}{*}{ Aroma } & Organic & $\begin{array}{l}\mathbf{7 . 0} \pm \mathbf{1 . 8}^{\mathrm{a}} \\
(2.8-10.1)\end{array}$ & $\begin{array}{l}6.3 \pm 1.6^{\mathrm{a}, \mathrm{b}} \\
(3.3-10.0)\end{array}$ & $\begin{array}{l}5.4 \pm 2.0^{b} \\
(2.4-9.7)\end{array}$ & 0.0004 \\
\hline & Conventional & $\begin{array}{l}7.4 \pm 1.3 \\
(5.5-9.9)\end{array}$ & $\begin{array}{l}6.9 \pm 1.7 \\
(3.2-10.1)\end{array}$ & $\begin{array}{l}7.1 \pm 1.7 \\
(3.2-10.0)\end{array}$ & 0.3267 \\
\hline & $P$-value ${ }^{\mathrm{iii}}$ & 0.2232 & 0.1106 & $<0.0001$ & \\
\hline \multirow[t]{3}{*}{ Sweet } & Organic & $\begin{array}{l}4.6 \pm 1.8 \\
(1.3-8.4)\end{array}$ & $\begin{array}{l}5.1 \pm 1.8 \\
(2.3-9.4)\end{array}$ & $\begin{array}{l}4.7 \pm 1.5 \\
(2.4-8.7)\end{array}$ & 0.4083 \\
\hline & Conventional & $\begin{array}{l}4.5 \pm 1.8^{b} \\
(1.9-10.2)\end{array}$ & $\begin{array}{l}\mathbf{5 . 3} \pm \mathbf{1 . 5}^{\mathrm{a}, \mathrm{b}} \\
(2.3-8.3)\end{array}$ & $\begin{array}{l}5.5 \pm 1.5^{\mathrm{a}} \\
(2.5-8.6)\end{array}$ & 0.0144 \\
\hline & $P$-value ${ }^{\mathrm{iii}}$ & 0.7209 & 0.5736 & 0.0284 & \\
\hline \multirow[t]{3}{*}{ Bitter } & Organic & $\begin{array}{l}2.4 \pm 1.2^{\mathrm{a}} \\
(1.0-5.2)\end{array}$ & $\begin{array}{l}2.0 \pm 0.9^{\mathrm{a}, \mathrm{b}} \\
(1.0-4.3)\end{array}$ & $\begin{array}{l}\mathbf{1 . 8} \pm \mathbf{0 . 8 ^ { b }} \\
(1.0-4.3)\end{array}$ & 0.0265 \\
\hline & Conventional & $\begin{array}{l}2.5 \pm 1.5 \\
(1.0-7.1)\end{array}$ & $\begin{array}{l}2.0 \pm 1.0 \\
(1.0-5.2)\end{array}$ & $\begin{array}{l}2.2 \pm 1.2 \\
(1.0-5.6)\end{array}$ & 0.2177 \\
\hline & $P$-value ${ }^{\mathrm{iii}}$ & 0.7743 & 0.9138 & 0.1255 & \\
\hline \multirow[t]{3}{*}{ Acid } & Organic & $\begin{array}{l}1.8 \pm 1.0 \\
(1.0-5.2)\end{array}$ & $\begin{array}{l}1.9 \pm 0.9 \\
(1.0-3.8)\end{array}$ & $\begin{array}{l}1.6 \pm 0.8 \\
(1.0-3.5)\end{array}$ & 0.4196 \\
\hline & Conventional & $\begin{array}{l}2.2 \pm 1.5 \\
(1.0-6.5)\end{array}$ & $\begin{array}{l}1.7 \pm 0.9 \\
(1.0-4.1)\end{array}$ & $\begin{array}{l}2.0 \pm 1.2 \\
(1.0-6.1)\end{array}$ & 0.2246 \\
\hline & $P$-value ${ }^{\mathrm{iii}}$ & 0.1729 & 0.4599 & 0.0638 & \\
\hline
\end{tabular}


Table 2 (continued)

\begin{tabular}{|c|c|c|c|c|c|}
\hline \multirow[t]{2}{*}{ Sensory attribute ${ }^{i}$} & \multirow{2}{*}{ Production mode } & \multicolumn{3}{|c|}{ Sweet pepper colour (i.e., maturation stage) } & \multirow[b]{2}{*}{$P$-value ${ }^{\mathrm{ii}}$} \\
\hline & & Green & Turning colour & Red & \\
\hline \multirow[t]{3}{*}{ Pungent } & Organic & $\begin{array}{l}1.9 \pm 0.9 \\
(1.0-3.8)\end{array}$ & $\begin{array}{l}2.0 \pm 1.2 \\
(1.0-4.8)\end{array}$ & $\begin{array}{l}\mathbf{1 . 7} \pm \mathbf{0 . 8} \\
(1.0-3.7)\end{array}$ & 0.3231 \\
\hline & Conventional & $\begin{array}{l}2.7 \pm 1.5^{\mathrm{a}} \\
(1.0-6.5)\end{array}$ & $\begin{array}{l}2.0 \pm 1.1^{b} \\
(1.0-4.8)\end{array}$ & $\begin{array}{l}2.2 \pm 1.4^{\mathrm{a}, \mathrm{b}} \\
(1.0-6.6)\end{array}$ & 0.0482 \\
\hline & $P$-value ${ }^{\mathrm{iii}}$ & 0.0045 & 0.9464 & 0.0481 & \\
\hline \multirow[t]{3}{*}{ Taste } & Organic & $\begin{array}{l}6.0 \pm 1.8^{\mathrm{a}} \\
(2.7-8.9)\end{array}$ & $\begin{array}{l}6.0 \pm 1.9^{\mathrm{a}} \\
(1.9-10.0)\end{array}$ & $\begin{array}{l}4.9 \pm 1.8^{\mathrm{b}} \\
(1.7-9.0)\end{array}$ & 0.0107 \\
\hline & Conventional & $\begin{array}{l}\mathbf{7 . 0} \pm \mathbf{1 . 6}^{\mathrm{a}} \\
(3.3-10.2)\end{array}$ & $\begin{array}{l}6.1 \pm 1.7^{b} \\
(2.8-9.2)\end{array}$ & $\begin{array}{l}6.8 \pm 1.5^{\mathrm{a}, \mathrm{b}} \\
(3.4-9.2)\end{array}$ & 0.0487 \\
\hline & $P$-value $\mathrm{e}^{\mathrm{iii}}$ & 0.0108 & 0.7463 & $<0.0001$ & \\
\hline \multirow[t]{3}{*}{ Hardness } & Organic & $\begin{array}{l}8.8 \pm 1.2 \\
(6.3-10.6)\end{array}$ & $\begin{array}{l}\mathbf{8 . 3} \pm \mathbf{1 . 2} \\
(5.6-10.0)\end{array}$ & $\begin{array}{l}8.5 \pm 1.3 \\
(5.4-10.2)\end{array}$ & 0.3366 \\
\hline & Conventional & $\begin{array}{l}8.6 \pm 1.4 \\
(5.6-10.4)\end{array}$ & $\begin{array}{l}8.5 \pm 1.1 \\
(6.4-10.2)\end{array}$ & $\begin{array}{l}8.2 \pm 1.1 \\
(5.6-9.5)\end{array}$ & 0.2260 \\
\hline & $P$-value ${ }^{\mathrm{iii}}$ & 0.5650 & 0.4396 & 0.2608 & \\
\hline \multirow[t]{3}{*}{ Fibrousness } & Organic & $\begin{array}{l}5.6 \pm 2.8 \\
(1.1-9.7)\end{array}$ & $\begin{array}{l}6.0 \pm 2.8 \\
(1.1-9.7)\end{array}$ & $\begin{array}{l}6.2 \pm 3.0 \\
(1.3-10.5)\end{array}$ & 0.6603 \\
\hline & Conventional & $\begin{array}{l}5.8 \pm 2.5 \\
(1.0-9.0)\end{array}$ & $\begin{array}{l}6.0 \pm 2.8 \\
(1.1-10.1)\end{array}$ & $\begin{array}{l}5.6 \pm 2.9 \\
(1.0-9.5)\end{array}$ & 0.8127 \\
\hline & $P$-value $e^{\text {iii }}$ & 0.6896 & 0.9968 & 0.4118 & \\
\hline \multirow[t]{3}{*}{ Crustiness } & Organic & $\begin{array}{l}8.9 \pm 1.4^{\mathrm{a}} \\
(5.8-10.6)\end{array}$ & $\begin{array}{l}8.4 \pm 1.4^{\mathrm{a}, \mathrm{b}} \\
(5.6-10.6)\end{array}$ & $\begin{array}{l}8.1 \pm 1.3^{b} \\
(5.5-10.4)\end{array}$ & 0.0447 \\
\hline & Conventional & $\begin{array}{l}8.9 \pm 1.3 \\
(4.9-10.4)\end{array}$ & $\begin{array}{l}8.5 \pm 1.4 \\
(5.3-10.5)\end{array}$ & $\begin{array}{l}\mathbf{8 . 2} \pm \mathbf{1 . 3} \\
(4.8-10.2)\end{array}$ & 0.0582 \\
\hline & $P$-value ${ }^{\mathrm{iii}}$ & 0.9484 & 0.6759 & 0.8272 & \\
\hline \multirow[t]{3}{*}{ Succulence } & Organic & $\begin{array}{l}\mathbf{9 . 0} \pm \mathbf{1 . 1}^{\mathrm{a}} \\
(5.0-10.6)\end{array}$ & $\begin{array}{l}8.1 \pm 1.4^{b} \\
(5.3-10.6)\end{array}$ & $\begin{array}{l}8.1 \pm 1.2^{b} \\
(5.4-10.5)\end{array}$ & 0.0014 \\
\hline & Conventional & $\begin{array}{l}8.2 \pm 1.4 \\
(5.7-10.3)\end{array}$ & $\begin{array}{l}8.3 \pm 1.2 \\
(5.0-10.2)\end{array}$ & $\begin{array}{l}8.3 \pm 1.4 \\
(4.6-10.0)\end{array}$ & 0.9860 \\
\hline & $P$-value $e^{\text {iii }}$ & 0.0079 & 0.5816 & 0.5361 & \\
\hline \multirow[t]{3}{*}{ Global quality } & Organic & $\begin{array}{l}8.0 \pm 1.3^{\mathrm{a}} \\
(3.9-10.4)\end{array}$ & $\begin{array}{l}7.3 \pm 1.3^{\mathrm{a}} \\
(5.2-10.2)\end{array}$ & $\begin{array}{l}6.6 \pm 1.4^{\mathrm{b}} \\
(3.4-9.6)\end{array}$ & $<0.0001$ \\
\hline & Conventional & $\begin{array}{l}8.0 \pm 1.4 \\
(5.6-10.5)\end{array}$ & $\begin{array}{l}7.5 \pm 1.3 \\
(4.5-10.3)\end{array}$ & $\begin{array}{l}7.9 \pm 1.3 \\
(5.6-10.7)\end{array}$ & 0.1966 \\
\hline & $P$-value $e^{\text {iii }}$ & 0.9138 & 0.5840 & $<0.0001$ & \\
\hline
\end{tabular}

${ }^{\mathrm{i} S e n s o r y ~ s e n s a t i o n s: ~ t h e ~ i n t e n s i t y ~ o f ~ e a c h ~ s e n s o r y ~ a t t r i b u t e ~ w a s ~ a s s e s s e d ~ b y ~ a ~ s e n s o r y ~ p a n e l ~ w i t h ~} 8$ trained panellists using a continuous scale ranging from 1 (absence of attribute perception) to 11 (maximum intensity perception).

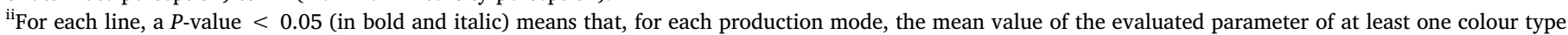
(i.e., maturation stage) differs from the others, according to the one-way ANOVA results (in this case multiple-comparison tests were performed). In each line, different small letters mean significant statistical differences of the parameter under evaluation, at a $5 \%$ significance level $(P$-value $<0.05)$, according to multiple comparison Tukey's HSD test.

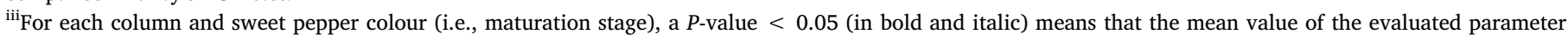
varied significantly with the production mode, according to $t$-Student test.

maturation stage, the production mode also had a significant impact. The results seem to indicate that in terms of global quality, and under the experimental conditions of this work, peppers produced following agronomic conventional mode had, in general, better physicochemical characteristics and a higher global quality.

\subsection{Discrimination of sweet peppers according to production mode and maturation stage}

3.2.1. PCA and LDA-SA models based on chemical-sensory data

As previously shown, the production mode as well as the maturation stage significantly influenced the chemical parameters and the sensory 


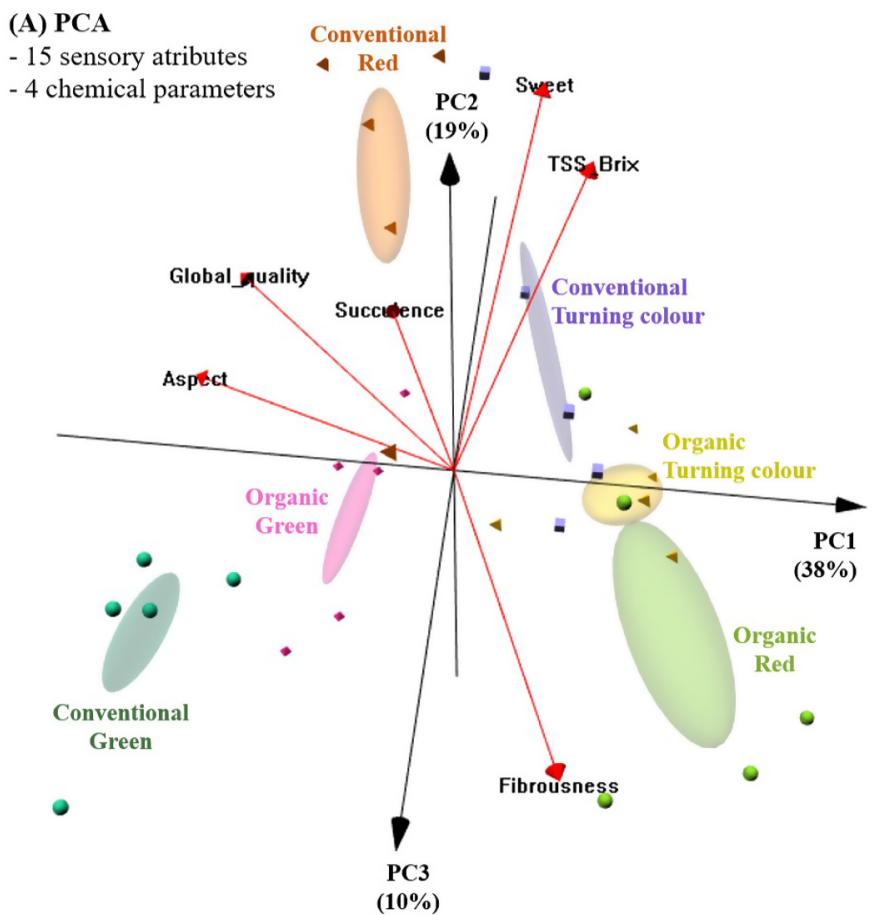

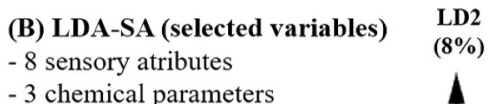

- 8 sensory atributes

-3 chemical parameters
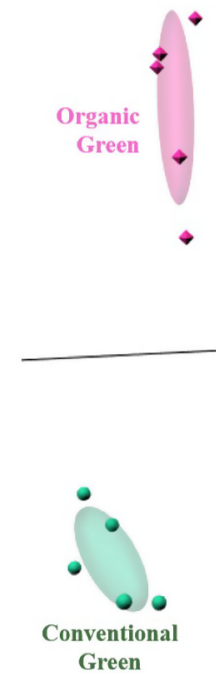

Green
D2

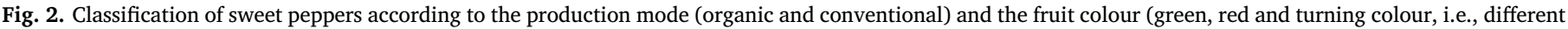

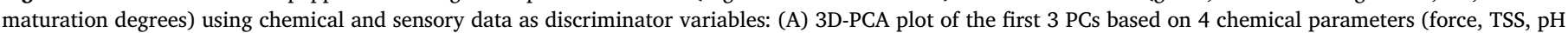

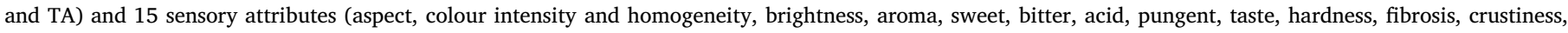

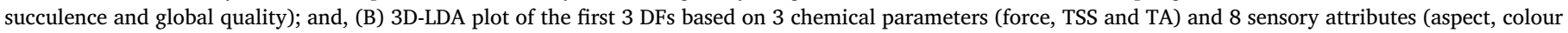
intensity, aroma, sweet, acid, taste, crustiness and global quality), selected using the SA algorithm.

profile. Thus, the possibility of using the chemical-sensory profile for the unsupervised classification of the sweet peppers according to the 6 levels of production mode/fruit colour (i.e., maturation stage) was evaluated using PCA. Fig. 2A showed that the 4 chemical parameters together with the 15 sensory attributes allowed a correct unsupervised split of the sweet peppers by production mode/fruit colour, based on the first 3 principal components (1st, 2nd and 3rd PCs explaining 67\% of the total variance). Indeed, it was possible to infer that, the chemicalsensory data would primarily allow differentiating the green sweet peppers from the others and, secondly, to discriminate the organic from the conventional production modes. To check this promising unsupervised classification performance, a LDA-SA approach was used. The results showed that it was possible to establish a LDA-SA model based on 11 parameters ( 3 chemical parameters: force, TSS and TA; and, 8 sensory attributes: aspect, colour intensity, aroma, sweet, acid, taste, crustiness and global quality). The first 3 significant linear discriminant (LD) functions explained $98 \%$ of the data variance allowing to correctly classify $100 \%$ (Fig. 2B) of the original grouped data (training) and only $80 \%$ of the data for the LOO-CV (internal-validation) procedure. In this latter case, the majority of the misclassification occurred between the organic and conventional turning colour sweet peppers. Taking into account that this CV variant is known as overoptimistic, the predictive performance of the LDA-SA model based on the 11 chemical-sensory parameters was further evaluated using the repeated $\mathrm{K}$-fold-CV procedure (4 folds and 10 repeats). With this more robust technique, which allowed to reserve $25 \%$ of the data (at least one sample from each of the 6 groups) for validation purposes, an average predictive sensitivity of $79 \pm 12 \%$ was achieved, pointing out that, although the referred parameters could be used to discriminate the sweet peppers, it only could be used as a preliminary tool.

\subsubsection{PCA and LDA-SA models based on E-tongue signal profiles}

E-tongues, namely potentiometric taste-sensors comprising nonspecific and cross-sensitive lipid sensor membranes, have been developed by the research team and successfully applied for qualitative and quantitative analysis of foods, like, for example, soft beverages [42], still and sparkling mineral waters [43], honey [44], table olives [19] and olive oil [20-22]. In this work, for the first time, the performance of a potentiometric E-tongue for discriminating sweet peppers according to the production mode and fruit colour (i.e., maturation stage) was investigated. Although the two E-tongue arrays comprised sensors with the same combinations of lipid additive/plasticizers/PVC and with the same relative composition (Fig. 1), they had different electrochemical properties since the manual drop-by-drop technique used to obtain the lipid sensor membranes originated inhomogeneous membranes with different physical properties (e.g., different membrane transparency levels and porosity leading to different adsorption phenomena and surface chemical reactions, which may be responsible for the different sensors' signals recorded for each sensor-sensor replica pair). Therefore, as pointed out by Veloso et al. [22], instead of assuming a set of 20 sensor-sensor replica membranes it was more realistic to consider that the lab-made E-tongue comprised 40 independent sensors. In fact, as can be inferred from Fig. 3, each sensor-sensor replica pair showed different signals profiles, which potentials varied within a $0-300 \mathrm{mV}$ range. However, it should be remarked that, for each agronomic mode and maturation stage, the raw potentiometric signals recorded (Fig. 3) by each of the 40 E-tongue sensors had \%RSD values ranging from 0.5 and $20 \%$, being in general lower than $15 \%$. First, PCA was carried out using the signal profiles recorded by the 40 sensors of the E-tongue, during the potentiometric analysis of the aqueous sweet pepper pastes. The results (Fig. 4A) showed that sweet pepper potentiometric fingerprints could be used for the unsupervised differentiation of green sweet peppers (organic or conventional) from the red and turning colour sweet peppers, although for these latter a high degree of samples overlapping was observed. The predictive classification capability of the E-tongue was deeply assessed using the LDA-SA approach. An E-tongue-LDA-SA model could be established based on the potentiometric profiles gathered by a selected sub-set of 


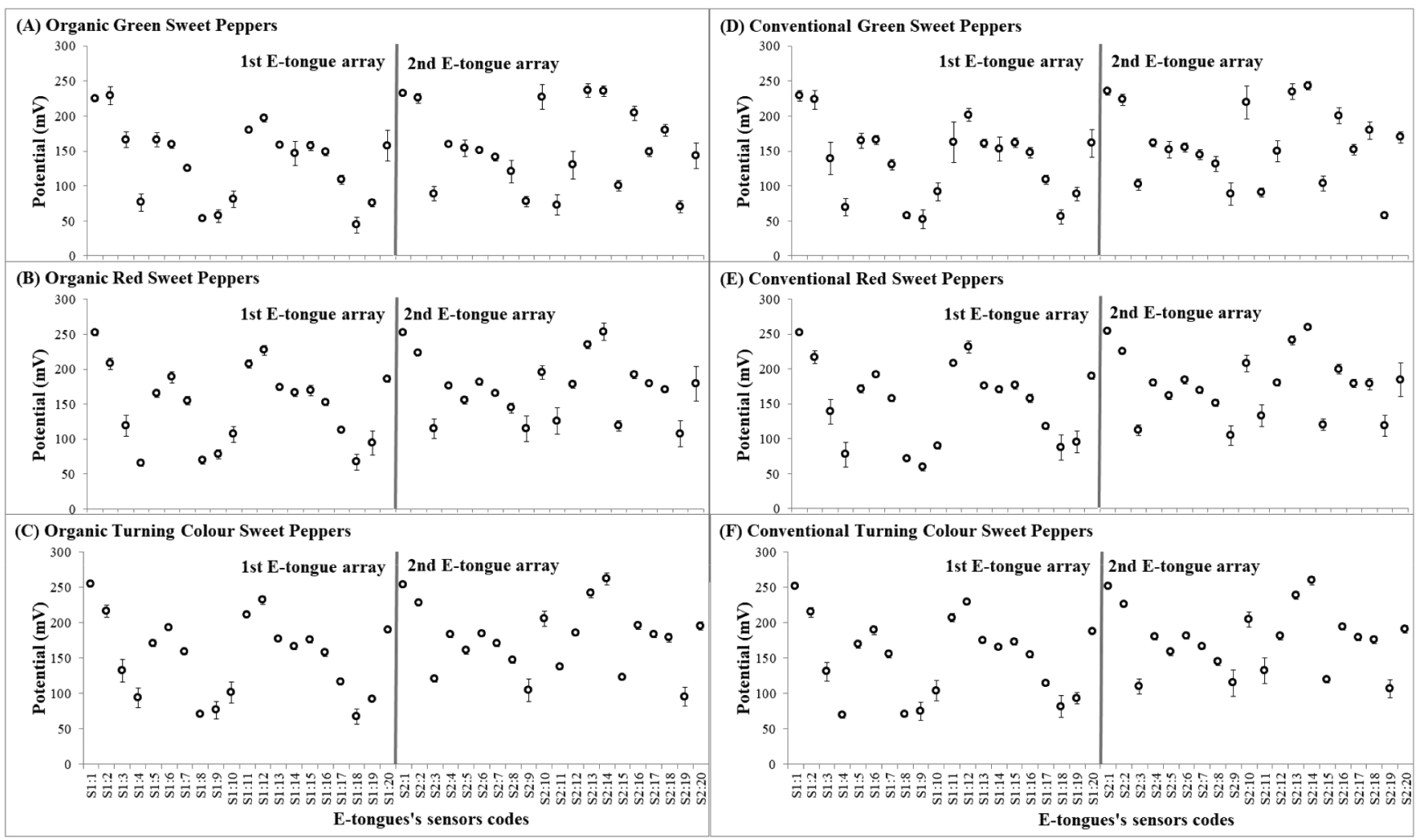

Fig. 3. E-tongue raw potentiometric signal $(\mathrm{mV})$ profiles recorded by the 40 E-tongue sensors during the analysis of the sweet peppers aqueous paste (mean values \pm standard deviation, for 5 independent samples evaluated per agronomic mode and maturation stage): (A) Organic green sweet peppers, (B) Organic red sweet peppers, (C) Organic turning colour sweet peppers, (D) Conventional green sweet peppers, (E) Conventional red sweet peppers, and (F) Conventional turning colour sweet peppers.
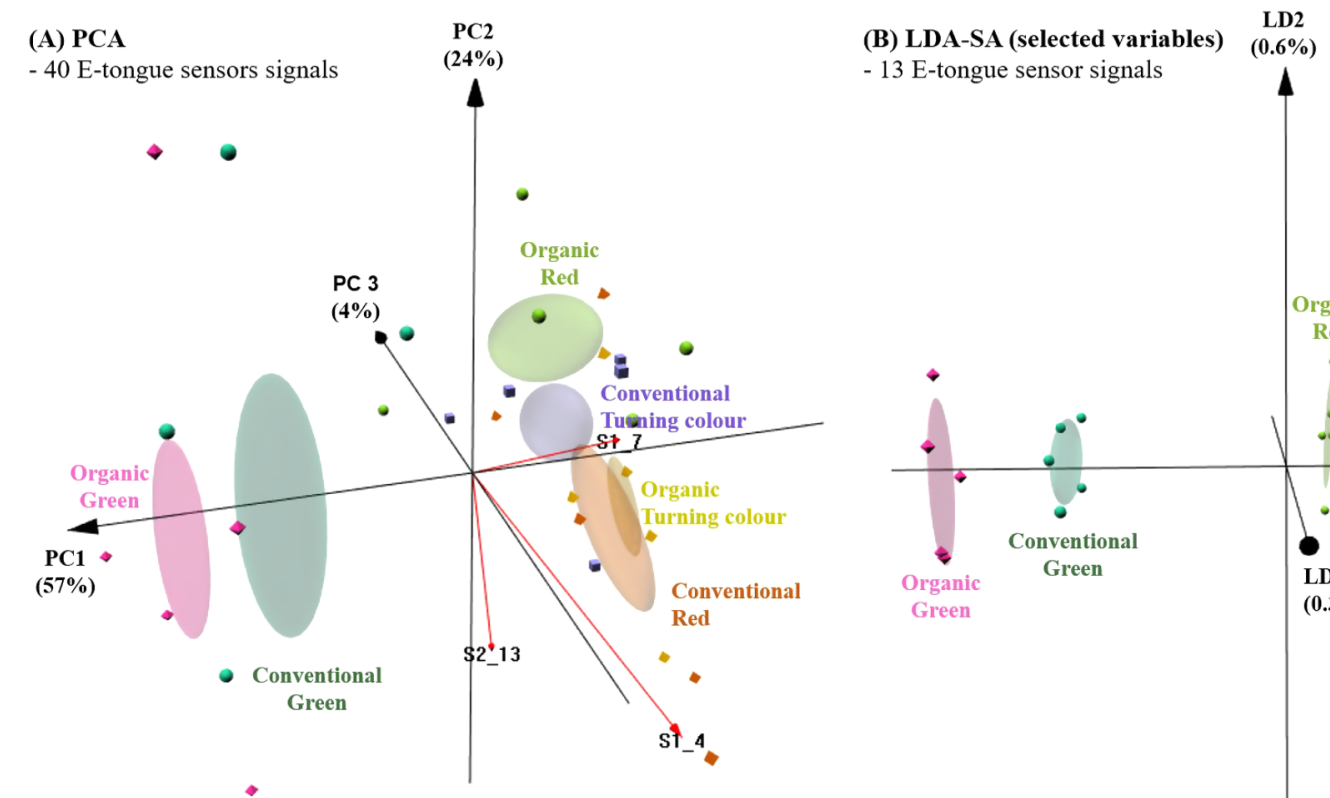

(B) LDA-SA (selected variables) $\quad(\mathbf{0 . 6} \%)$
-13 E-tongue sensor signals

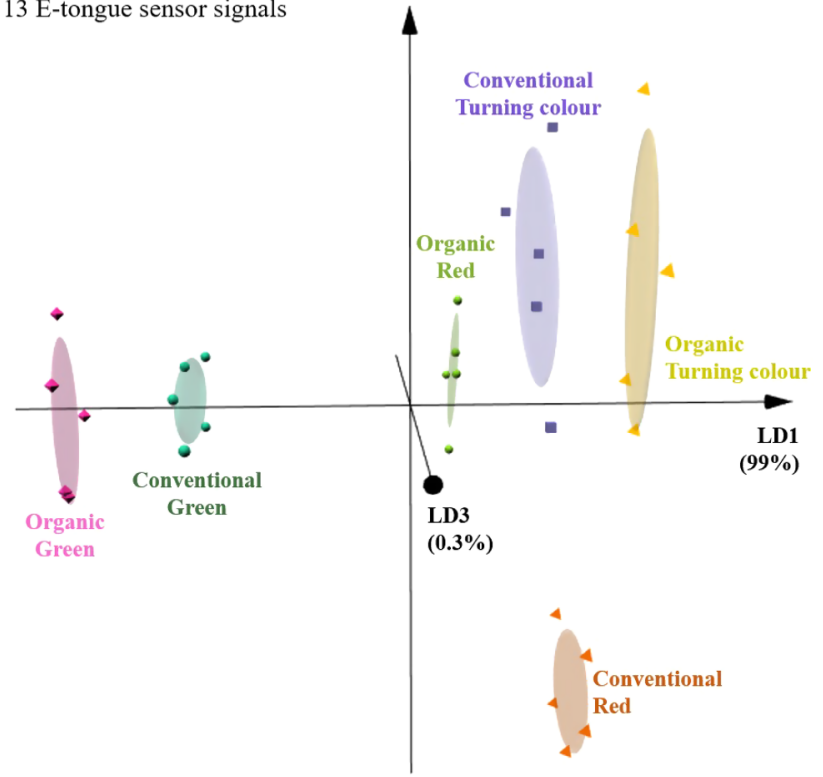

Fig. 4. Classification of sweet peppers according to the production mode (organic and conventional) and the fruit colour (green, red and turning colour, i.e., different maturation degrees) using the E-tongue signal profiles as discriminator variables: (A) 3D-PCA plot of the first 3 PCs based on the potentiometric signals gathered by the 40 E-tongue sensors (S1:1 to S1:20, S2:1 to S2:20); and, (B) 3D-LDA plot of the first 3 DFs based on 13 E-tongue sensors (S1:5, S1:9, S1:10, S1:12, S1:14, S1:18, S2:3, S2:4, S2:8, S2:10, S2:13, S2:16 and S2:18), selected using the SA algorithm. 
13 sensors (S1:5, S1:9, S1:10, S1:12, S1:14, S1:18, S2:3, S2:4, S2:8, S2:10, S2:13, S2:16 and S2:18), explaining the first 3 discriminant functions $99.9 \%$ of the data variance. The multivariate linear model allowed $100 \%$ of correct classifications for the original grouped data (Fig. 4B) and 90\% for the LOO-CV (turning colour sweet peppers from conventional production showed the greatest number of misclassified samples), showing a better accuracy compared to the LDA-SA model previously established based on 11 chemical-sensory parameters. The predictive classification performance was further checked according to the repeated K-fold-CV internal-validation procedure ( 4 folds $\times 10$ repeats) resulting in an average sensitivity of $85 \pm 9 \%$. This result confirmed the superiority of the E-tongue discrimination model, showing that it could be used as a practical and more accurate tool for a preliminary recognition of the sweet pepper production mode and maturation stage. This achievement also pointed out that the potentiometric E-tongue could be used as an indirect taste sensor, since by allowing assessing the fruit colour, it also indirectly evaluates the evolution trends of the sweet, bitter, pungent and acid taste sensations. Although these attributes can be perceived by trained panellists, the availability of sensory panels is scarce. Moreover, the sensory evaluation by panellists may pose several limitations, such as panellists score subjectivity, analysis cost and low number of samples that can be evaluated per day, which may be minimized or partially overcome using this type of E-tongue as a prospective routine analytical tool.

\section{Conclusions}

The study carried out allowed confirming that the physicochemical composition and sensory attributes of sweet peppers are highly dependent on the agronomic production mode and on the maturation stage. For the conditions evaluated and the variety Entinas studied, it could be concluded that, in general, sweet peppers produced under the organic production mode had a better visual and tactile quality and lower chemical quality than fruits produced using agronomic conventional practices. On the other hand, the production mode and the fruit's maturation stage did not had a significant effect on olfactory and gustatory attributes neither on the peppers' global quality, although a significant effect was found on the visual aspect sensory attributes. Moreover, the work pointed out that the physicochemical and sensory data could be used to satisfactorily classify the studied peppers according to the production mode-maturation stage. Finally, it was also demonstrated, for the first time, that a potentiometric electronic tongue could be successfully used as a preliminary taster sensor for correctly discriminating sweet peppers according to the conventional or organic production mode and taking into account the fruits' colour. This finding allows foreseen the electronic tongue as a possible complementary sensory analysis tool that could be applied for overcoming the known shortcomings of the sensory panels, namely their scarcity and reduced number of samples that can be daily evaluated.

\section{Declaration of Competing Interest}

The authors declare that they have no known competing financial interests or personal relationships that could have appeared to influence the work reported in this paper.

\section{Acknowledgments}

The authors are grateful to the Foundation for Science and Technology (FCT, Portugal) and FEDER under Program PT2020 for financial support to CIMO (UIDB/00690/2020) and to CEB (UIDB/ 04469/2020) units and to BioTecNorte operation (NORTE-01-0145-FEDER-000004) funded by the European Regional Development Fund under the scope of Norte2020 - Programa Operacional Regional do Norte. Nuno Rodrigues thanks to National funding by FCT- Foundation for Science and Technology, P.I., through the institutional scientific employment program-contract.

\section{Appendix A. Supplementary data}

Supplementary data to this article can be found online at https:// doi.org/10.1016/j.microc.2020.105034.

\section{References}

[1] P.M. Eggink, C. Maliepaard, Y. Tikunov, J.P.W. Haanstra, A.G. Bovy, R.G.F. Visser, A taste of sweet pepper: Volatile and non-volatile chemical composition of fresh sweet pepper (Capsicum annuum) in relation to sensory evaluation of taste, Food Chem. 132 (2012) 301-310, https://doi.org/10.1016/j.foodchem.2011.10.081.

[2] N. Baenas, M. Belović, N. Ilic, D.A. Moreno, C. García-Viguera, Industrial use of pepper (Capsicum annum L.) derived products: Technological benefits and biological advantages, Food Chem. 274 (2019) 872-885.

[3] M. Massey, A. O'Cass, P. Otahal, A meta-analytic study of the factors driving the purchase of organic food, Appetite 125 (2018) 418-427.

[4] Willer, H., \& Lernoud, J. (Eds.). (2018). The world of organic agriculture. Statistics and emerging trends 2018. Research Institute of Organic Agriculture (FiBL), Frick and IFOAM - Organics International, Bonn.

[5] S. Denver, J.D. Jensen, S.B. Olsen, T. Christensen, Consumer preferences for 'Localness' and organic food production, Journal of Food Products Marketing 25 (2019) 668-689.

[6] M. de Rocha C., Deliza, R., Corrêa, F.M., Carmo, M.G.F.D., \& Abboud, A.C.S. A study to guide breeding of new cultivars of organic cherry tomato following a consumerdriven approach Food Research International 512013265273.

[7] T. Barzegar, M. Fateh, F. Razavi, Enhancement of postharvest sensory quality and antioxidant capacity of sweet pepper fruits by foliar applying calcium lactate and ascorbic acid, Sci. Hortic. 241 (2018) 293-303.

[8] G. Caruso, E. Cozzolino, A. Cuciniello, R. Maiello, V. Cenvinzo, M. Giordano, S. de Pascale, Y. Rouphael, Yield and quality of greenhouse organic pepper as affected by shading net in Mediterranean area, Acta Hortic. 1268 (2020) 335-339.

[9] Food Chem. 311 (2020) 125910, https://doi.org/10.1016/j.foodchem.2019. 125910.

[10] E. Hallmann, K. Marszałek, J. Lipowski, U. Jasińska, R. Kazimierczak, D. ŚrednickaTober, E. Rembiałkowska, Polyphenols and carotenoids in pickled bell pepper from organic and conventional production, Food Chem. 278 (2019) 254-260.

[11] Sci. Hortic. 263 (2020) 109107, https://doi.org/10.1016/j.scienta.2019.109107.

[12] N. Sinelli, L. Cerretani, V. Di Egidio, A. Bendini, E. Casiraghi, Application of near (NIR) infrared and mid (MIR) infrared spectroscopy as a rapid tool to classify extra virgin olive oil on the basis of fruity attribute intensity, Food Res. Int. 43 (2010) 369-375.

[13] C. Eckert, M. Pein, J. Reimann, J. Breitkreutz, Taste evaluation of multicomponent mixtures using a human taste panel, electronic taste sensing systems and HPLC, Sens. Actuators, B 182 (2013) 294-299.

[14] C. Apetrei, F. Gutierez, M.L. Rodriguez-Mendez, J.A. de Saja, Novel method based on carbon paste electrodes for the evaluation of bitterness in extra virgin olive oils, Sens. Actuators B Chem. 121 (2007) (2007) 567-575.

[15] Apetrei FN: 2010 C. Apetrei, I.M. Apetrei, S. Villanueva, J.A. de Saja, F. GutierrezRosales, M.L. Rodriguez-Mendez, et al. Combination of an e-nose, an e-tongue and an e-eye for the characterisation of olive oils with different degree of bitterness Anal. Chim. Acta 663201020109197.

[16] Apetrei FN: 2012 I.M. Apetrei, C. Apetrei, et al. Detection of virgin olive oil adulteration using a voltammetric e-tongue Comput. Electron. Agric. 10820142012 148154 10.1016/j.compag.2014.08.002.

[17] Rodríguez-Méndez FN: 2008 M.L. Rodriguez-Mendez, C. Apetrei, J.A. de Saja, et al. Evaluation of the polyphenolic content of extra virgin olive oils using an array of voltammetric sensors Electrochim. Acta 532008200858675872 10.1016/j.electacta.2008. 04.006.

[18] N. Rodrigues, L.G. Dias, A.C.A. Veloso, J.A. Pereira, A.M. Peres, Monitoring olive oils quality and oxidative resistance during storage using an electronic tongue, LWT-Food Science and Technology 73 (2016) 683-692.

[19] Í.M. Marx, N. Rodrigues, L.G. Dias, A.C.A. Veloso, J.A. Pereira, D.A. Drunkler, A.M. Peres, Quantification of table olives' acid, bitter and salty tastes using potentiometric electronic tongue fingerprints, LWT-Food Science and Technology 79 (2017) 394-401.

[20] T.H. Borges, A.M. Peres, L.G. Dias, I. Seiquer, J.A. Pereira, Application of a potentiometric electronic tongue for assessing phenolic and volatile profiles of Arbequina extra virgin olive oils, LWT-Food Science and Technology 93 (2018) 150-157.

[21] U. Harzalli, N. Rodrigues, A.C.A. Veloso, L.G. Dias, J.A. Pereira, S. Oueslati, A.M. Peres, A taste sensor device for unmasking admixing of rancid or winey-vinegary olive oil to extra virgin olive oil, Comput. Electron. Agric. 144 (2018) 222-231.

[22] A.C.A. Veloso, L.M. Silva, N. Rodrigues, L.P. Rebello, L.G. Dias, J.A. Pereira, A.M. Peres, Perception of olive oils sensory defects using a potentiometric taste device, Talanta 176 (2018) 610-618

[23] Y. Vlasov, A. Legin, A. Rudnitskaya, C. Di Natale, C. D’Amico, Nonspecific sensor arrays ("electronic tongue") for chemical analysis of liquids: (IUPAC technical report), Pure Appl. Chem. 77 (2005) 1965-1983.

[24] Y. Kobayashi, M. Habara, H. Ikezazki, R. Chen, Y. Naito, K. Toko, Advanced taste 
sensors based on artificial lipids with global selectivity to basic taste qualities and high correlation to sensory scores, Sensors 10 (2010) 3411-3443.

[25] Í. Marx, N. Rodrigues, L.G. Dias, A.C.A. Veloso, J.A. Pereira, D.A. Drunkler, A.M. Peres, Sensory classification of table olives using an electronic tongue: analysis of aqueous pastes and brines, Talanta 162 (2017) 98-106.

[26] S. Slim, N. Rodrigues, L.G. Dias, A.C.A. Veloso, J.A. Pereira, S. Oueslati, A.M. Peres, Application of an electronic tongue for Tunisian olive oils' classification according to olive cultivar or physicochemical parameters, Eur. Food Res. Technol. 243 (2017) 1459-1470.

[27] A.C.A. Veloso, L.G. Dias, N. Rodrigues, J.A. Pereira, A.M. Peres, Sensory intensity assessment of olive oils using an electronic tongue, Talanta 146 (2016) 585-593.

[28] D. Bertsimas, J. Tsitsiklis (1992), Simulated annealing, Stat. Sci. J. 10-15.

[29] J. Cadima, J.O. Cerdeira, M. Minhoto, Computational aspects of algorithms for variable selection in the context of principal components, Comput. Stat. Data Anal. 47 (2004) 225-236.

[30] S. Kirkpatrick, C.D. Gelatt, M.P. Vecchi, Optimization by simulated annealing, Science 220 (1983) 671-680.

[31] W.N. Venables, B.D. Ripley, Modern Applied Statistics with S (Statistics and Computing), 4th edn., Springer, New York, 2002.

[32] K.M. Selahle, D. Sivakumar, J. Jifon, P. Soundy, Postharvest responses of red and yellow sweet peppers grown under photo-selective nets, Food Chem. 173 (2015) 951-956.

[33] L. Aslani, M. Mobli, J. Keramat, Comparison of anti-oxidant activities and fruit quality attributes in four sweet bell pepper (Capsicum annuum L.) cultivars grown in two soilless media, J. Hortic. Sci. Biotechnol. 91 (2016) 497-505.

[34] E.R. Bayogan, R. Salvilla, A.M. Carmela Majomot, J. Acosta, Shelf life of two sweet pepper (Capsicum annuum) cultivars stored at ambient and evaporative cooling conditions, South-Western Journal of Horticulture, Biology and Environment 8 (2017) 1-15.

[35] J. Gajc-Wolska, K. Mazur, M. Niedzińska, K. Kowalczyk, P. Zołnierczyk, The influence of foliar fertilizers on the quality and yield of sweet pepper (Capsicum annuum L.), Folia Horticulturae 30 (2018) 183-190.

[36] S.N. Jimenez-Garcia, M.A. Vázquez-Cruz, R. Miranda-Lopez, L. Garcia-Mier, R.G. Guevara-González, A.A. Feregrino-Perez, Effect of Elicitors as Stimulating Substances on Sensory Quality Traits in Color Sweet Bell Pepper (Capsicum annuum L. cv. Fascinato and Orangela) Grown under Greenhouse Conditions, Polish Journal of Food and Nutrition Sciences 68 (2018) 359-365.

[37] J. Almeida Alves, P. Nogueira Curi, R. Pio, E. dos Santos Penoni, M. Pasqual, V. Rios de Souza, Characterization, processing potential and drivers for preference of pepper cultivars in the production of sweet or spicy jellies, J. Food Sci. Technol. 56 (2019) 624-633.

[38] H.A. Ibrahim, M.A.A. Abdullah, Effects of 1-methylcyclopropane on quality of tomato and sweet pepper fruits during mixed loads, Bioscience Research 15 (2018) $270-279$.

[39] A. Ibrahim, H. Abdel-Razzak, M. Wahb-Allah, M. Alenazi, A. Alsadon, Y.H. Dewir, Improvement in growth, yield, and fruit quality of three red sweet pepper cultivars by foliar application of humic and salicylic acids, HortTechnology 29 (2019) $170-178$.

[40] Agronomy 9 (11) (2019) 730, https://doi.org/10.3390/agronomy9110730.

[41] A.L. Brantsæter, T.A. Ydersbond, J.A. Hoppin, M. Haugen, H.M. Meltzer, Organic food in the diet: Exposure and health implications, Annu. Rev. Public Health 38 (2017) 295-313.

[42] L.G. Dias, C. Sequeira, A.C.A. Veloso, M.E.B.C. Sousa, A.M. Peres, Evaluation of Healthy and Sensory Indexes of Sweetened Beverages using an Electronic Tongue, Anal. Chim. Acta 848 (2014) 32-42.

[43] L.G. Dias, Z. Alberto, A.C.A. Veloso, A.M. Peres, Electronic tongue: a versatile tool for mineral and fruit-flavored waters recognition, J. Food Meas. Charact. 10 (2016) 264-273.

[44] M.E.B.C. Sousa, L.G. Dias, A.C.A. Veloso, L. Estevinho, A.M. Peres, A.A.S.C. Machado, Practical procedure for discriminating monofloral honeys with a broad pollen profile variability using an electronic tongue, Talanta 128 (2014) 284-292. 